\title{
Cross-Cultural Experiential Learning Excursion: The Story of Awakening and Awareness: A Case Study
}

\author{
Gary Cheeseman (Maajiiange) \\ American Indian Storytelling and Critical Pedagogy Resources Center, University of South Dakota, Delzell, USA
}

\begin{abstract}
This is a case study that critically explored issues of diversity in a state with a large American Indian population. Despite the success of some universities many are still struggling to identify the characteristics of a healthy diversified campus as evidenced by the constant scrutiny of higher education accreditation bodies. The scrutiny stems from a wide range of issues including: aspects of institutional life, student enrollment and retention, faculty engagement, curriculum development and institutional outcomes. Perhaps the most important challenge facing many universities is the need to improve the effectiveness of their diversity initiatives. In fact, many universities are feeling a heightened sense of urgency to improve their initiatives as well as generate positive diversity outcomes. The Cross-Cultural Experiential Learning Excursion (C-CELE) is an initiative that provides a profound experience using diverse pedagogies including Indigenous and critical pedagogies that places agents of change throughout the institution and around key faculties.
\end{abstract}

Keywords: diversity, experiential learning, pedagogy, higher education, diversity initiatives, education, inclusivity

\section{Introduction}

There is a broad assumption that heightened levels of awareness might perpetuate cultural understanding across a university campus; however, many educational institutions still struggle with the diversity goals of higher education accreditation bodies and governmental policy that advocates change toward more inclusive environments (Boyd \& Owens, 2012).

American colleges and universities ought to be multilayered culturally sophisticated institutions that propagate critical thought and emotional reflection knowing that critical thought and emotional reflection will lead to positive relationships and enhanced awareness (Antonio, Chang, Hakuta, Kenny, Levin, \& Milem, 2004) and that enhanced awareness might lead to change.

The assumption that drove this study is that critical thought and emotional reflection within the larger context of experiential learning might influence the establishment and maintenance of positive relationships and lead to increased awareness between diverse people at the university.

Unfortunately critical thought and emotional reflection may not always translate into positive relationships across campus, but it does challenge traditional assumptions by creating a learning community that fosters discourse (Giroux, 2003). Consequently universities ought to invest in something that creates discourse.

The question that encouraged this study is, "Can a three day Cross-Cultural Experiential Learning Excursion

Gary Cheeseman (Maajiiange), Ph.D., Associate Professor, American Indian Storytelling and Critical Pedagogy Resources Center, School of Education, Division of Curriculum and Instruction, University of South Dakota. 
(C-CELE), focused on American Indian culture, challenge traditional assumptions and help inspire the cultural awareness of its participants?" In addition, "what happens to self in the context of increased awareness?"

The researcher gathered formal data from 2 focus groups, conversations with participants and informal data from question and answer periods and classroom discussion. Feedback was collected, analyzed, coded, categorized and put into a comprehensive narrative that could become part of a larger body of research that might creatively enhance cultural awareness.

\section{Cross-Cultural Experiential Learning Excursion}

Participants volunteered to partake in a 3-day, facilitator led bus excursion (rolling classroom) through American Indian reservations and other historically, culturally, politically, and spiritually significant sites in South Dakota, Nebraska and Wyoming. The C-CELE was designed to intellectually, emotionally and spiritually challenge participants by exposing them to some of the complicated realizations of American Indian culture and circumstance. Participants were asked to gauge their levels of awareness when they started the excursion, compare it with their levels of awareness at various points during the C-CELE, and report on the findings through focus group discussions that were held during the C-CELE.

The C-CELE was designed to focus strictly on building awareness. An important objective was to avoid having the C-CELE devolve into an anthropological fishbowl thus; participants were constantly reminded to utilize experiential learning techniques, critical thinking and reflective thought to foster transformative learning (Duffy \& Jonassen, 1992).

\section{Facilitator}

The facilitator was acutely aware of the C-CELE's sensitive nature. He was not an "Indian guru" but a culturally traditional native man who teaches a variety of American Indian and Social Justice courses using experiential, critical and Indigenous pedagogies.

A successful learning experience was contingent on the facilitator's ability to effectively transform experience using diverse pedagogies and relevant content (Atkinson \& Murrell, 2012; Itin, 1999; Kayes, 2002; Kolb, 1984; Piaget, 1962; Stutsky \& Laschinger, 1995). The facilitator consistently used informal assessment techniques to gather the data necessary in understanding the learning challenges of the participants. The feedback allowed the participants and facilitator to collaborate in the creation of a communicative process that enhanced understanding and the foundation of a critical learning environment.

It was the facilitator's responsibility to encourage the participants to think critically about their dissonance and other emotional states of being. The facilitator needed the participants to "think about what they were thinking about" and then ask themselves "why am I thinking this way".

\section{Literature Review}

Diversity is complex and defining it is challenging. This study broadly defined and based its definition on the critical thinking theories rooted in the concepts of social equality. A broad definition of diversity is necessary when teaching about cultural difference because it ought to allow for the explorative examination of inequality, in depth discussion, and multiple perspectives. This definition is consistent with educational definitions found in several similar studies (Bowen \& Hackett, 2010; Watts, 2010).

Campus diversity enhances student success (Jayakumar, 2008) and disseminates cultural engagement and critical thought by challenging people to move beyond cultural isolation (Jarvis, 2006). In short, educational 
diversification is designed to perpetuate a philosophy of equal opportunity (Antonio et al., 2004; Bourdieu, 1999).

A well-documented higher education objective is to create a critical mass of underrepresented people to attain and retain a healthy interchange of ideas (Smith, 2009) that ensure the civic mission of the country (Brown \& Bell, 2008), an objective that many campuses are unable to achieve (Solorzano, Ceja, \& Yosso, 2000). Consequently, many diverse students, faculty and staff find themselves in an unbearable environment filled with social alienation, academic disengagement and self-doubt that could lead to poor performance (Giroux, 2003).

There have been many attempts to use a variety of techniques to diversify colleges and universities in the United States (Laird, Engberg, \& Hurtado, 2005). Some attempts have been interactive, others comprehensive, and others critically reflective (LaNasa, Cabrera, Transgrud, \& Alleman, 2007). Interactive initiatives occasionally referred to as "low hanging fruit" are (Nelson-Lairad, 2005) culturally scripted informational, academic and social events designed to congregate culturally diverse people. They are generally well suited for settings where people work with others of even standing (Antonio, 2001; Bocian, 1997).

A second more comprehensive level of diversity initiative introduces students to social actualities such as privilege, power, empathy and equality (Brooks \& Ward, 2007; Delgado \& Stefancic, 2001; Hytten \& Warren, 2003). This level could incite higher levels of cognitive dissonance because it address sensitive issues that assign culpability. Educators at this level may encounter complex classroom situations, guilt and cognitive dissonance (Hytten \& Warren, 2003). A third level, critical reflection, helps students recognize the divergent relationship between privilege and underrepresentation by illuminating the signs, symbols and processes associated with the dominions of oppression. Critical reflection enables students the opportunity to test and apply theoretical perspectives that scrutinize those dominions (Wenger, 1998) by exposing the inequitable aspects of the student's own cultural icons. Students might gain a deeper understanding of how oppression affects the disenfranchised across society in a variety of ways.

\section{Learning Through Experience}

The supporting assumptions of this study are that people learn better from experience and that teachers ought to create an environment in which better learning can occur (Dewey, 1938; Wurdinger, 2005).

Experiential learning is rooted in the discipline of social psychology and the theories of experiential philosophy and cognitive pragmatism. This study emphasized the theoretical constructs of Joplin (2008) and Kolb (1984), both of whom believe that much of what we learn occurs through environmental change. Both Joplin (2008) and Kolb (1984) argue that experiential learning is about using the physical presence to holistically enhance the learning process and recognize the cognitive process of transforming experience into knowledge.

The transformation of experience into knowledge is an important part of understanding and doing anything well. Experiential learning is pragmatic in nature and a necessary component of the learning process (Kolb, 1984). Kolb (1984) described experiential learning as a series of steps within a process that ultimately forms a learning cycle and that learners can enter the cycle at any step. Kolb (1984) broke down the steps into two paradigms. Kolb called the first paradigm concrete experience and abstract conceptualization,which occurs after learners understand the experience. Kolb (1984) called the Second paradigm reflective observation and active experimentation, which enables the learner to convertan experience into knowledge. 
Experiential learning, in its most basic form is described in two ways. The first is informal and the other is when the learner is formally exposed to a particular set of circumstances. The second type of experiential learning is that in which the C-CELE is patterned. However, both are present and allowed to flourish.

Experiential learning is cumulative and over time allows for enhanced interaction and reflective understanding (Rea, 2006). In addition, research shows that experiential learning enhances cognitive recall (Vygotsky, 1978), fosters powerful learning transmissions (Piaget, 1962) and inspires reflection and peer-to-peer communication, something often missing within the classroom. In other words, experiential learning allows for the formulation of one's own story.

\section{Storytelling}

Stories allow people to awaken their natural curiosity and desire for information and experience personal images, descriptions and feelings. Stories provide an opportunity to build personal relationships across diverse domains and to build and retain the meaning of community, truth and purpose. Stories are universally told and allow access to the future and the past as they assist in the process of enjoying life.

In this study, the researcher wanted to reveal the true essence of how the participants felt throughout the C-CELE. The qualitative nature of storytelling allows for opportunities to articulate sophisticated interpretations of experiential events in personal ways.

\section{Qualitative Analysis}

Storytelling is closely associated with the theories of qualitative research. The theoretical perspectives associated with qualitative research are: Constructivist, Critical, Post-positivist, Postmodern and Feminism (Creswell, 2008), all of which examine the human experience through indiscriminate, subjective, multifaceted methods of analysis (Borbasi \& Jackson, 2012); all of which extract data from the human experience as it is articulated through story. Qualitative analysis is behavior based and supports human understanding (Borbasi \& Jackson, 2012) by producing data that helps understand the complexities of diversity through discussion. Qualitative analysis does not over simplify or diminish data into a number (Creswell, 2008). Within this study the researcher used qualitative exploration to follow a subjective pathway (storytelling) through a particular methodology(case study) (Creswell, 2008).

\section{Case Study}

The researcher used a "Social Case Study" method to guide the research process. A case study refers to the collection of detailed information (Creswell, 2008), in this case, the study of data extracted from a small group of people that participated in a diversity initiative. This case study looked closely at conclusions that only apply to a specific context; in this case did participation in the C-CELE increase awareness. This research did not concentrate on the discovery of a comprehensive actuality and it was not seeking to discover cause-effect relationships. This study was designed to formulate an explorative description of heightened awareness.

Case studies are ideal when the researcher is asking questions that cannot be explained by a chart or table. It is also preferred when the researcher's focus is within the context of real life. Case studies use inductive logic and require a question that seeks out a holistic interpretation of a particular event or condition.

\section{Research Design}

\section{Participants}

This study consisted of 14 female and 10 male participants. Of the 14 females; 7 had terminal degrees, 2 
were master students and 2 had undergraduate degrees. Of the females with terminal degrees, 3 were professors, 2 were librarians and 2 were university administrators. Of the 10 males 7 had terminal degrees, 2 had master degrees, and 1 had an undergraduate degree. Of the 7 males with terminal degrees, 4 were professors and 3 were administrators. The average female age was 39 with an average 8 year higher education tenure. The average male age was 40 with an average 13 year higher education tenure. Of the female participants, 13 identified as "Caucasian" and 1 as African American. Of the 10 male participants, 7 identified as "Caucasian", 1 as African, one as African American, and 1 as Latina.

The questions were designed to extract the profound meaning of the participant's experiences. The researcher was interested in particular comments that might signify changes in opinion or challenges to traditional beliefs.

\section{Data Collection Questions}

The following are the questions and statements used within the focus groups: (1) Speak about any aspect of the excursion that may have physically, intellectually, emotionally, or spiritually stimulated you either negatively or positively; (2) Explain why you may or may not have been stimulated by particular events; (3) Describe the educational value of the excursion; (4) Speak about your own personal learning experiences; and (5) Is there anything else you want to say about your C-CELE experience?

\section{Data Collection}

Bracketing. The researcher was extremely conscious of personal bias. Bracketing helped the researcher avoid personal prejudices throughout the process of data collection and analysis (Creswell, 2008; Moustakas, 1994).

\section{Focus Groups}

Focus group facilitator. Creswell (2008) suggests that effective, experienced facilitators enable participants to tell their own often-intimate story within the context of the research theme. The focus group facilitator has conducted more than 35 focus groups sessions and is a professional mediator. He met the group at both locations to conduct the focus group sessions. The facilitator guided the conversation and observed the verbal and non-verbal behaviors of the participants.

Focus group method and procedure. Focus groups capture unique perspectives by converging on important data and is often more comprehensive and consequential than other methodologies (Morgan \& Krueger, 1998). Focus groups suit the phenomenological theory well because they inspire participants to tell their story.

The facilitator explained the objectives of the focus groups. Participants indicated that they understood and were eager to share their perspectives. Participants sat in a circle for both focus groups each of which lasted about 75 minutes. Both focus groups were recorded for accuracy.

\section{Data}

Analysis. To ensure reliability the researcher transcribed every statement twice. Discrepancies were analyzed and corrected and then matched against a third transcription to ensure accuracy. Next, the transcribed data were analyzed for relevant themes; the process was then repeated to ensure accuracy. The researcher then began the tenuous coding process. After the data was coded, the researcher set it aside for several days and then repeated the process to ensure reliability. The coding revealed potential categories and after a great deal of 
consideration and analysis, thematic categories began to take shape. The researcher repeated the process and reexamined discrepancies before beginning to develop an objective summary using the learner's exact words (individual textual descriptions). The researcher developed two types of interpretative summative descriptions - the first for the individual participant, which evolved into the second across the experiences of all participants. The researcher interpreted the meanings of the experience (Moustakas, 1994) and summarized the experiences of the study's participants.

Data revealed. The data revealed that participant responses were rooted primarily in emotional descriptors. For the purposes of accuracy and reliability, the researcher categorized the data using the participants' own descriptors.

Guilt. This participant's response was indicative of five others.

"I always seem to go to the same place; I know I feel guilty and I wish they (Natives) could have all the privileges that I have, but I feel as if I am still looking at it through my Western eyes."

Other participants used synonyms like "regretful", "ashamed", and "humble" to describe their feelings of guilt.

This participant seemed sympathetic to Natives as he spoke about the divergence of two cultural perspectives.

"I am not walking in the same shoes and not seeing (life) in the same way as Indian people. I am seeing what I saw for the past two days from my point of view; you know how to fix those that were wronged. I feel very regretful."

This participant resorted to his instincts; interestingly he seemed to recognize what those instincts were.

"I want to see the loose ends tied up, but I also know after seeing what I saw on this trip, I know that white people are not going to fix the complications. I am ashamed to think that white people feel that they can fix the world's problems."

Upset. Some participants were upset with what they saw. This participant and nine others saw unexpected levels of poverty.

"I was upset with the general poverty and the lack of infrastructure; I had heard that it was bad but didn't expect it to be that bad."

Other participants used emotionally identifying words like "ashamed", "unhappy", "sad", and "helpless" to align themselves with feelings of being upset.

The C-CELE exposed participants to the issues of absolute poverty, causing many to think about being more conscientious while others felt helpless. This participant struggled with the complex ramifications of poverty and the effects it has on the Native population.

"I saw something different... the different side-effects of poverty on the reservations like how it all mixes with cultural issues; things like wanting to stay with the families. I don't know if there is a way to escape it as you can in some other cultures. It makes me unhappy. ”

Other participants, familiar with the effects of poverty indicated that they came from poverty and were surprised that they saw it in the middle of America. This participant spoke about his experience.

"I was born and raised in Texas about ten miles from the Mexican border; the neighborhoods that we saw today were not a surprise because I grew up in that kind of poverty. I am sad that I feel so helpless and that we allow this to exist."

This participant expressed the feelings of others, 
"I guess what is most bothersome is this feeling of helplessness. It's one thing to know about the reality of other places in the world but what we saw today, sheer poverty, is hard to swallow."

This participant expanded,

"I believe that we come from the most advanced culture and the poverty, the extreme poverty, is right here and I feel helpless."

This participant also expressed feelings of helplessness,

"I was thinking about this notion of helplessness because I know that I am helpless in terms of putting myself in (American Indians') position; I am not Native."

Other participants indicated the same feelings,

"I don't know how to resolve these feelings of helplessness... I feel sad... I want to understand."

This participant worked with Native Elders in various addiction programs on the reservation. Seeing White Clay reminded her of those experiences.

"I was saddened by what I saw but I am glad that I saw it. With time you tend to forget and this experience enabled me to refresh what I should have been thinking about for a while."

This participant worked with Native children for a summer and explained her unique perspective:

"I worked with a lot of native students last summer and spent a lot of time getting to know a lot of people on the reservation. I saw some kids that were in trouble and that's their reality; just like what we live is our reality and some of the things that they had to deal with were heart breaking."

Seeing White Clay tugged at me at a very emotional level.

Anger. Seven of the participants were feeling angry by what they saw. Some phraseology associated with anger included "outrage" and "irritation". This participant reiterated what others said:

"I am still having a hard time processing all my thoughts; White Clay had such an impact because I have studied the poverty of the world; especially in other countries but I don't think I have ever seen poverty so severely compounded by all the other issues on the reservations. It's an outrage."

With tears in his eyes this participant spoke about his reaction to White clay, Nebraska:

"The thing that affected me most and irritates me most is still affecting me is, I began to realize how we as human beings prey on other people's misfortune. I saw on one side of the street how two people were drinking out of brown paper bags and on the other side of the street I saw this middle aged man laying down in front of a building in broad daylight, clearly intoxicated. I could only extrapolate that he is just a young man and that ten years down the line he will be in an even more difficult situation."

This participant elaborated on his feelings about the Wounded Knee Memorial in Wounded Knee, South Dakota,

"The thing that irritated me the most after talking to (Native people at Wounded Knee) was that they seem to be in a constant struggle, and they were so nice."

Inadequateness. Many of the participants questioned the effort to improve conditions on the reservations; six participants spoke about struggles using identifying words such as "inferior", "ineffective", and "useless". 
This participant summed up what several others said,

"It seems to me that there have been plans that have been (on the reservation) for a while; some of which should have succeeded by now. Something about the whole thing seems incomplete."

This participant measured what he saw based on solidified pre-conceived notions and not hearing about the many success stories on the reservations.

"I thought I would see all kinds of success stories there and I know there is, but there should be more. It seems that there has been plenty of time. If people keep trying, well if they are like me, it would make the effort feel like a waste of time; it would all be useless."

This participant spoke about cultural paternalism,

“Historically we haven't been very effective and we are responsible for messing up (American Indian) culture. We have been trying to help out Native people ever since we arrived on the Mayflower, and it seems like we haven't done anything right."

Caring. Participants were emotional throughout the C-CELE. Seven participants exposed dichotomous perspectives and used phraseology such as "sympathy", "respect", and "beauty". This participant spoke about his personal feelings,

"If you look around at the beauty of the land...it made me feel at peace, but... it was also emotionally trying."

Fighting tears, this participant attempted to explain his anxiety,

"The unrest that I know exists there and the extreme poverty class with...I mean I have such respect for (American Indians) and their culture but it brings up more questions than can be answered; I don't think we white people have the answers anyway."

This participant, like many others who spoke about life on the reservations, wanted to help,

"I wish there was something I could do to help out and make life on the reservation better. It seemed to me that the people that I talked to were happy and very grateful."

Confusion. Many participants were confused throughout the C-CELE and expressed it during the focus groups. Some of the statements contained key words and phrases such as "wondering", "taken aback", and "confused". This participant was hearing information that he did not expect:

"I am a veteran and actually standing in the Wounded Knee graveyard was saddening. I am wondering how or why someone from the Indian community would ever participate in the armed services. I am wondering if American Indian people believe in service to their country especially after the political turmoil that this government has caused Indian people."

This participant wanted to share what she knows about military service and her experience in Indian country:

"If you go to Indian powwows they spend an immense amount of time celebrating the veterans. They spend time honoring people that have gone to war so think about their ability to overcome and how unwilling we are to overcome. Participating in the ceremony at Wounded Knee reminded me of how much Natives have overcome and how much they still celebrate life. I will be forever thankful.”

This participant was confounded by one of the elder looking people at Wounded Knee: 
"What really hit me was when the gentleman was talking right before the ceremony that we did at Wounded Knee. He spoke about the issue of identity and he used the term 'strongman'. He asked me if I was a strongman and I was really taken aback. He asked me if I ever got a passport. I told him I had and then the man asked me if I knew who I was based on the fact that I was able to get a passport. Then the man looked at me and asked, 'But what are you? I am Lakota I remember who I am, what are you?' That sense of indifference or identity is one sense I sort of feel as I looked at the Wounded Knee memorial. It seems to be one of those things that the US doesn't want to remember."

Another participant spoke about the issue of identity and self-validity,

"Being a white person I don't often understand the reason for clinging to identity; I know that Natives know the reason."

Grateful. The final emotion that emerged from the C-CELE was that participants felt fortunate to have had the learning opportunity.

This participant's statement was profound because she realized that being on the C-CELE helped her understand herself,

"Being white is hard (at Wounded Knee). Standing in the graveyard made me think about my own identity, something I never think about. I suppose because I don't really have to."

This participant and six others spoke about seeing things from a different perspective. The researcher is not convinced that all of the learners reached levels of empathy, but many seem more sympathetic to or aware of the issues of American Indian people.

"I think I am at a place where I think I am seeing things a little different. Kind of from another culture's perspective thanks to this experience; but that barrier is still there and I think that education, especially this type of education, is the key, and I wish that this sort of thing (C-CELE) could be expanded in a way that more people can experience other cultures and start opening the door so more people can feel the kind of emotion that we are feeling and see beyond the way they still see things."

This participant along with three others emphasized the need to see it (Native culture) in order to understand this culture and truly understand empathy.

"For me it is about not being so theoretical when we are in the classroom where it's about statistics and formulated conjecture, where we might have a couple of slides or a PowerPoint or be made to take the class online and get nothing out of it or see some pictures of what it could be and stuff, but right now we are actually seeing it and it is helping me relate and I am for one very grateful."

This participant and one other spoke from a more pragmatic perspective:

"Maybe we need more practicality. Maybe we need to see it and that is where the change comes from and that is really nice for me because I am a really tactile and visual learner."

This participant and three others on the C-CELE spoke about how they need to interact with students better. They feel as if they gained some tools that will enable them to better meet their students' needs:

"I am happy that I have a better context of what is happening out there, and I feel as if I have a better understanding of the Native students that I deal with. Sometimes they have to leave because they know someone who committed suicide or there may be problems with the family and they have to leave. I have seen one Native female with a full ride. She had to go home and ended up losing her ride, so there you go; we are struggling trying to keep our Native students; that makes this a great thing." 
This learner added,

“The emotion we are all feeling is interesting. I don't think I have ever thought at such a deep level; I am glad I had the opportunity to participate."

\section{Discussion}

The C-CELE is a learning community (Lave \& Wenger, 1991) invested in the acquisition of knowledge (Gray \& Gibbons, 2002; Rocha, 2007) using diverse pedagogies such as storytelling, demonstration, critical analysis and location (Eraut, 1994).

According to the data, participants indicated that they were heavily engaged and motivated by experiential epistemology. Their exchange of stories and ideas shaped the larger narrative and become the story of the excursion. The melding of their stories created ownership of the process and deep learning.

The participants indicated that critical thinking promoted inquisitive learning throughout the process. The C-CELE emphasized four criterion: recognizing and investigating assumptions, seeking multiple perspectives on a given subject, building rapport through communication, and fostering active involvement. The participants indicated that when they focused on these principles they began to incorporate and synthesize information through critique.

Participants were asked to continuously reflect on the learning process, an important goal of the C-CELE (Loughran, 2002). The concept of reflection is popular in education and a necessary aspect of the C-CELE. Participants were reminded that reflecting on the experience is what leads to profound levels of learning (Loughran, 2002). The facilitator was constantly reminding the participants to think reflectively and informally discuss their feelings with him. It was through informal discussion that 4 important factors were identified as important to the learning and imperative to the acquisition of awareness.

(1) Factor 1: The rolling classroom as well as the sites provided a theater were a wealth of information was easily accessible. Participants were able to effectively use the plentiful learning spaces and allow the experiences to occur. It was at the point of occurrence were participants indicated that they felt "awake" to the issues at hand.

(2) Factor 2: The participants indicated that they always felt safe and included and that the establishment of an affective learning community would not have been possible without feeling safe. Many of the participants indicated that becoming aware could only be possible in an environment in which they felt "safe enough" to internally explore.

(3) Factor 3: Most of the participants indicated that they appreciated the space to think for themselves. It was important that the learning environment encouraged critical thinking skills andindividual analysis. Nearly every participant spoke about how important it was to step out of his or her comfort zone and think critically about the issues at hand. A few indicated that they never thought about thinking before and that thinking about issues is what made them aware.

(4) Factor 4: Participants needed to have fun in the process. Nearly every participant commented on the C-CELE's wide variety of experiences and that even though the days were long and extremely emotional at times, they were able to keep the learning process meaningful and in context. It was important that the participants had the opportunity to laugh. Many indicated that the C-CELE would be far too intense without the laughter.

Scholars like to think of universities as institutions that inspire free thinking and critical thought. Historically universities have led the charge toward social change in the United States; however, many still 
struggle with the remnants of preservationist ideologies that inhibit healthy progressive deliberation and social inspiration.

This study originated in a state with little diversity but a significant American Indian population. The university at the center of this study (The $U$ ) has little diversity and few American Indian students.

The $U$ has struggled to sustain successful diversity initiatives. Designed to be both innovative and profound, the C-CELE was an attempt to investigate whether a progressive approach would work to dispel the barriers that restrict awareness by bringing participants face to face with what they do not know or perhaps with what they fear.

Revealing data emerged from the focus groups. Most poignantly the data indicated that the participants were cognizant and emotionally engaged in the phenomenon and nearly every participant perceived a heightened sense of emotional vigilance; which according to their testimony, enhanced their levels of cultural awareness. Participants also indicated that they better understood American Indian people. Nearly all of the participants denoted that the experience was more than a personal struggle or epistemological diversion. For some, the C-CELE reshaped their sociocultural context.

This study's findings correlated with Baer, Smith, and Allen (2004), who revealed that experiential situations heighten emotional reaction and that emotional reaction toward content in association with experience generated profound levels of knowledge acquisition, which, according to the data from this study, had positive repercussions that transferred into awareness.

\section{Conclusion}

In the end, this study is just the beginning. The C-CELE is an awakening but merely a snapshot of a particular event at a particular time. There is much work to be done. For example, research on the concept of emotional learning and research on the pedagogical processes of experiential learning, both would be logical extensions of this project.

Although the research from this study is not transferable, it does point out that new initiatives can have a profound affect on understanding that might lead to awareness.

The other prevalent issue is that participants volunteered to participate in the C-CELE; it would be interesting to facilitate a group who were mandated to partake. The research plan is to follow-up on the different phases with a longitudinal study to investigate how the case study affected participants over time as well as changes to the campus climate.

\section{References}

Antonio, A. L., Chang, M. J., Hakuta, K., Kenny, D. A., Levin, S., \& Milem, J. F. (2004). Effects of racial diversity on complex thinking in college students. Psychological Science, 15(8), 507- 510.

Antonio, A. L. (2001). The role of interracial interaction in the development of leadership skills and cultural knowledge and understanding. Research in Higher Education, 42, 61.

Atkinson, G., \& Murrell, P. H. (2012). Kolb's experiential learning theory: A meta-model for career exploration. Journal of Counseling and Development, 66(8), 374-377.

Baer, R. A., Smith, G. T., \& Allen, K. B. (2004). Assessment of mindfulness by self-report. The Kentucky inventory of mindfulness skills. Assessment, 11(3), 191-206. doi:10.1177/1073191104268029

Borbasi, S., \& Jackson, D. (2012). Navigating the maze of research. Chatswood, Sydney: Mosby Elsevier.

Bocian, M. (1997). Housing on college campuses: Self-segregation, integration and other alternatives. Retrieved from:http:// www.eric.ed.gov/PDFS/ED446596.pdf 
Bourdieu, P. (1999). Acts of resistance: Against the tyranny of the market. NY, NY Press.

Bowen, G. A., \& Hackett, P. B. (2010). Developing cultural understanding through Spanish-language learning: A service-learning approach. Journal on Excellence in College Teaching, 21(2), 29-43.

Boyd, T., \& Owens, T. (2012). Education Sector Strategy 2020 and popular participation: Parallels and pitfalls. In C. S. Collins, \& A. W. Wiseman (Eds.), Education strategy in the developing world: Revising the World Bank's education policy (pp. 81-109). Emerald Group Publishing Limited.

Brooks, D. E., \& Ward, C. J. (2007). Assessing students' engagement with pedagogies of diversity. Journal of Mass Communication Educator, 62(3), 250-251.

Brown, K., \& Bell, J. (2008). Demise of the talented tenth: Affirmative action and the increasing underrepresentation of ascendant blacks at selective higher educational institutions. Columbus, O. H.: Ohio State Press.

Brown, P., Lauder, H., \& Ashton, D. (2011). The global auction: The broken promises of education, jobs, and incomes. New York, NY: Oxford University Press.

Chomsky, N. (1999). Profit over people: Neoliberalism and the global order. New York. Seven Stories Press.

Creswell, J. W. (2008). Research design: Qualitative, quantitative, and mixed methods approaches. Los Angeles, C.A.: Sage.

Delgado, R., \& Stefancic, J. (2001). Critical race theory: An Introduction. New York, N.Y.: NYU Press.

Duffy, T., \& Jonassen, D. H. (Eds.). (1992). Constructivism and the technology of instruction: A conversation. Hillsdale, N.J.: Erlbaum.

Dewey, J. (1938). Experience and education. New York, N.Y.: Macmillan.

Eraut, M. (1994). Developing professional knowledge and competence. London, England: The Falmer Press.

Fields, S. (2014). '90s view: Diversity in the approaching millennium. Diverse Issues in Higher Education, 31 (3), 12.

Giroux, H. (2003). Youth, higher education, and the crisis of public time: Educated hope and the possibility of a democratic future. Social Identities, 9, 141-168.

Gray, M., \& Gibbons, J. (2004). Critical thinking as integral to social work practice. Journal of Teaching in Social Work, 1(24), 19-38.

Hytten, K., \& Warren, J. (2003). Engaging Whiteness: How racial power gets reified in education. Qualitative Studies in Education, 16(1), 527-543.

Itin, C. (1999). Reasserting the philosophy of experiential education as a vehicle for change in the 21 st century. The Journal of Experiential Education, 22(2), 91-98.

Jayakumar, U. M. (2008). Can higher education meet the needs of an increasingly diverse and global society? Harvard Education Review, 78(4), 615-651.

Jarvis, P. (2006). Toward a comprehensive theory of human learning. London, England: Routledge.

Joplin, L. (2008). On defining experiential education. In K. Warren, D. Mitten, \& T. A. Loeffler (Eds.), Theory and practice of experiential education (pp. 3-15). Boulder, C.O.

Kayes, C. D. (2002). Experiential learning and its critics: Preserving the role of experience in management learning and education. Academy of Management Learning and Education, 1(2), 137-149.

Kolb, D. A. (1984). Experiential learning: Experience as the source of learning and development. Englewood Cliffs, N.J.: Prentice-Hall.

LaNasa, S. M., Cabrera, A. F., Transgrud, H., \& Alleman, N. (2007). Engagement as a proxy for learning: Testing Pascarella's "Model of engagement", with NSSE items. Paper presented at the Annual Meeting of the Association for the Study of Higher Education, Louisville, K.Y.

Lave, J., \& Wenger, E. (1991). Situated learning: Legitimate peripheral participation. New York, Cambridge University Press.

Laird, T. F., Engberg, M. E., \& Hurtado, S. (2005). Modeling accentuation effects: Enrolling in a diversity course and the importance of social action engagement. Journal of Higher Education, 76(4), 448-486.

Locks, A. M., Hurtado, S., Bowman, N. A., \& Oseguera, L. (2008). Extending notions of campus climate and diversity to students' transitions to college. Review of Higher Education, 31(3). 257-285.

Loughran, J. J. (2002). Effective reflective practice. Journal of Teacher Education, 55, 33-43. doi: 10.1177/0022487114552028.

Morgan, D. L., \& Krueger, R. A. (1998). The focus group kit. Thousand Oaks, C. A.: Sage Publications.

Moustakas, C. (1994). Phenomenological research methods. Thousand Oaks, C.A.: Sage Publications.

Nelson-Laird, T. F. (2005). College students' experiences with diversity and their effects on academic self-confidence, social agency, and disposition toward critical thinking. Research in Higher Education, 36, 369-370.

Pascarella, E. T., \& Terenzini, P. T. (2005). How college affects students: A third decade of research. San Francisco, C.A.: Jossey-Bass. 
Piaget, J. (1962). The construction of reality in the child (Translated by Margaret Cook). New York, N.Y.: Basic Books.

Rea, T. (2006). It's not as if we've been teaching them... reflective thinking in the outdoor classroom. Journal of Adventure Education \& Outdoor Learning, 6(2), 121-134.

Rocha, C. J. (2007). Engaging students in macro issues through community-based learning. Journal of Teaching in Social Work, $27,3-4$.

Solorzano, D., Ceja, M., \& Yosso, T. (2000). Critical race theory, racial microaggressions, and campus racial climate: The experiences of African American college students. Journal of Negro Education, 69(1-2), 60.

Smith, D. G. (2009). Diversity's promise for higher education: Making it work. Baltimore, M.D.: Johns Hopkins University Press.

Stutsky, B. J., \& Laschinger, H. K. S. (1995). Changes in student learning styles and adaptive learning competencies following a senior preceptorship experience. Journal of Advanced Nursing, 21(1), 143-153.

Tarabini, A. (2010). Education and poverty in the global development agenda: Emergence, evolution and consolidation. International Journal of Educational Development, 30, 204-212.

Vygotsky, L. S. (1978). Mind in society. Cambridge, M.A.: Harvard University Press.

Watts, C. (2010). The addition of service-learning to a social studies methods course. National Social Science Journal, 34(1), 157-160.

Wenger, E. (1998). Communities of practice: Learning, meaning, and identity. New York, N.Y.: Cambridge University Press.

Wurdinger, S. (2005). Using experiential learning in the classroom: practical ideas for all educators. Lanham, M.D.: Rowman \& Littlefield. 